\title{
Investigation of the Behavior of Steel Shear Walls Using Finite Elements Analysis
}

\author{
Kamran Abubakri \\ Department of Civil Engineering \\ Mahabad Branch, Islamic Azad University \\ Mahabad, Iran. \\ Kamran.Abubakri13@chmail.ir
}

\author{
Hedayat Veladi \\ Department of Structural Engineering \\ Faculty of Civil Engineering, University of Tabriz \\ Tabriz, Iran. \\ hveladi@tabrizu.ac.ir
}

\begin{abstract}
Currently, steel shear walls are considered by engineers as an economic method against lateral loads imposed by wind and earthquake in tall structures. Accordingly, there is a growing need to develop accurate methods alongside approximation methods to estimate the behavior of these structural elements. The finite element technique is one of the strongest numerical methods in analysis of solid mechanics problems. Finite element analysis however requires high technical knowledge of the behavioral models of materials. Therefore, it is less used by designers for certain structural elements such as steel shear walls. This study examines the failure mechanism of steel shear walls using finite elements analysis and validates this modeling by comparing the results with experimental studies.
\end{abstract}

Keywords-steel shear wall; nonlinear analysis; post-buckling behavior; cyclic loading; lateral loading system

\section{INTRODUCTION}

The most important challenge that engineers face during the design and construction of tall buildings is to design a good lateral loading system with the ability to tolerate wind and earthquake forces, particularly in high-rise buildings. One of the solutions for this problem is to use steel shear walls. Several international regulations accept and allow this solution, for example the Canadian regulation CAN/CSA S16-01. According to this regulation, an equivalent brace, rather than any steel plate, is considered after distribution of the horizontal force at the height of the structure. In [1-3] the history of steel shear walls is described in detail. Structurally, a steel shear wall is composed of a steel plate in the center with peripheral beams and columns. Steel shear walls act like a cantilever steel plate beam in which columns are the wings of the plate beam, story beams (story bridges) are stiffeners and the steel plate is the web. Empirical studies conducted so far have led to a comprehensive understanding of the behavior of this lateral loading system. These studies address the ductile connections between the plate and its frame, behavior of the infill plates, strength and stiffness of the system and others [4, 7-9]. In addition to laboratory studies, extensive studies have been conducted regarding numerical modeling of steel shear walls. In [12] the precise estimations of time periods in structures equipped with steel shear wall was discussed. Moreover, there are many ongoing studies on reinforced steel shear walls. In [6] the system was reinforced by carbon fiber polymers. In [5] the effect of stiffeners and the connection between central beam and peripheral frame on mechanical behavior of the structure with steel shear wall was studied using finite element analysis.

\section{BEARING SYSTEMS OF STEEL SHEAR WALLS}

Steel shear wall consists of a thin steel plate, two boundary columns and horizontal beams in which the steel plates are connected by welding or bolts to the peripheral frame. It is also possible to use longitudinal and transverse stiffeners to reinforce steel plate. Figure 1 shows the schematic details of a steel shear wall with stiffener. Two main factors of the lateral load-resisting systems such as bracing systems, steel shear walls, moment-consuming frames, and concrete shear walls include stiffness and strength which are determined by loaddisplacement diagram. Currently, there are three general methods for analysis of steel shear walls: 1) strip model, 2) frame-plate interaction or the Sabouri method which is used here to control the results of finite element modeling [10, 11], 3) finite element method.

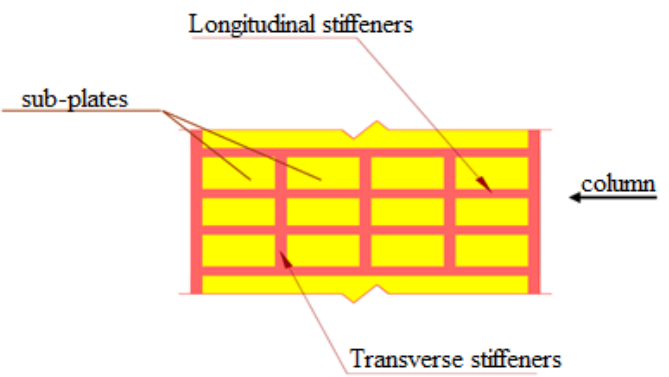

Fig. 1. Steel shear wall with stiffeners

In the strip model presented by researchers at the University of Alberta, Canada [2, 3, 9] shear panels are modeled as a series of diagonal strip members which are only able to tolerate tensile forces in the same direction of main tensile stresses. The strip model is only limited to steel shear walls with thin plates. Moreover, this model provides no solution for steel shear walls with openings or stiffeners. To eliminate these problems, a 
general method to analyze and design steel shear walls in different scenarios with and without stiffeners, with and without opening, with thin and thick plate was proposed in [10, 11]. This method evaluates the behavior of plate and frame separately, and considers the interaction of these two elements together. This model is called frame-plate interaction and its modeling through the use of finite element analysis can prove highly time and cost effective as well as accurate.

\section{VALIDATION OF FINITE ELEMENT METHOD IN MODELING STEEL SHEAR WALL}

This section validates the finite element modeling of steel shear walls by ANSYS software. Figure 2 compares the output of the finite element modeling in ANSYS software and results of the experiment on one-story steel shear wall with a thin plate at the University of British Columbia. The comparison between load-displacement curves shows that the computerized model is in a good agreement with the experiment.

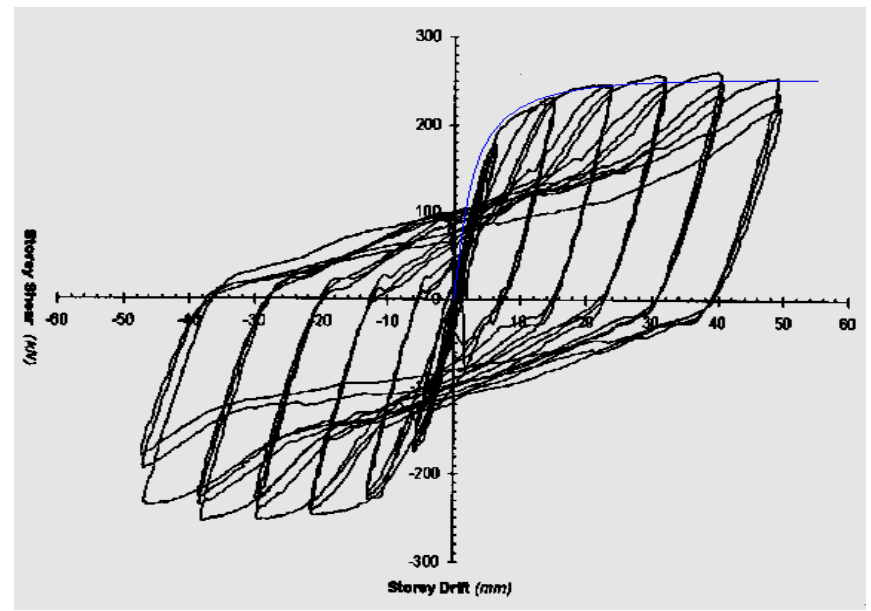

Fig. 2. Comparison of the finite element results (blue ANSYS) and the sample tested under cyclic load (Black)

\section{FAILURE BEHAVIOR OF STEEL SHEAR WALL FOR TESTED SAMPLES WITH 0.7 MM IN THICKNESS}

This section presents the force-displacement curve obtained from finite element nonlinear analysis for laboratory samples of [13] which is the frame of an opening equipped with shear wall. Table I lists the geometry of the samples tested in [13]. Figures 3 to 5 compare the force-displacement curves obtained from finite element modeling by this study and experimental results from [13].

TABLE I. GEOMETRY OF SAMPLES WITH 0.7 MM IN THICKNESS FOR STEEL PLATE

\begin{tabular}{|c|c|c|c|}
\hline Sample & $\begin{array}{c}\text { Height of story } \\
\text { (h in cm) }\end{array}$ & $\begin{array}{c}\text { Width of opening } \\
\text { (b in cm) }\end{array}$ & $\begin{array}{c}\text { Aspect ratio } \\
(\mathbf{h} / \mathbf{b})\end{array}$ \\
\hline 1 & 120 & 170 & 0.706 \\
\hline 2 & 120 & 120 & 1 \\
\hline 3 & 170 & 120 & 1.42 \\
\hline
\end{tabular}

As shown in Figures 3 to 5, modeling and experimental results are reasonably close to each. In all samples, the stiffness of finite element analysis by ANYSY is higher than the stiffness of the experimental models.

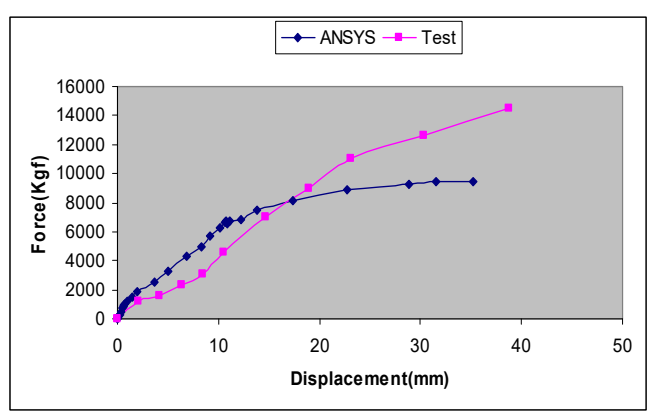

Fig. 3. Force-displacement curve obtained from finite element analysis for sample 1

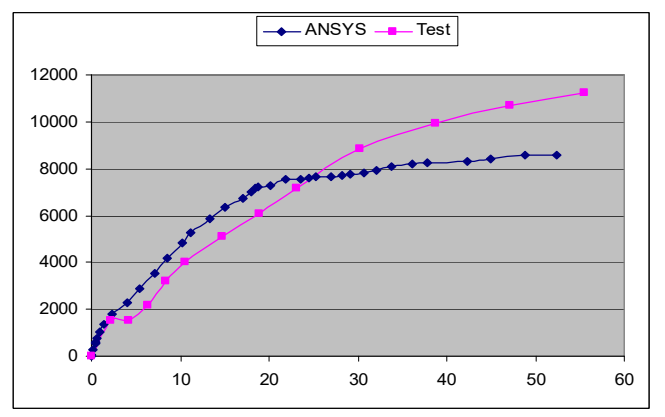

Fig. 4. Force-displacement curve obtained from finite element analysis for sample 2

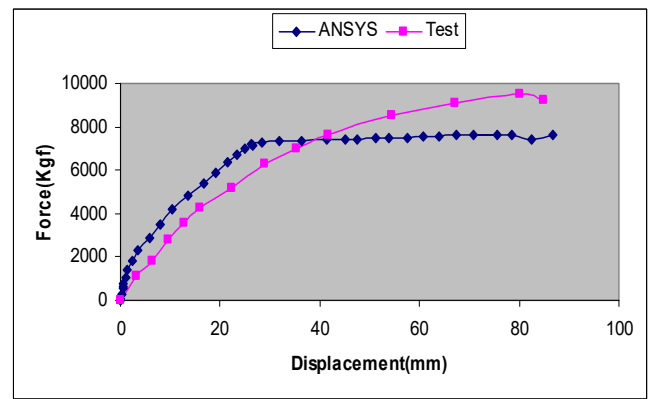

Fig. 5. Force-displacement curve obtained from finite element analysis for sample 3

Figure 6 shows the finite element results as loaddisplacement curves for all samples. Obviously, the increase in aspect ratio of the panel reduces stiffness. Table II lists the stiffness obtained for all samples. Clearly, the increase in aspect ratio reduces stiffness. Figure 7 shows the effect of changes in aspect ratio of the panel on the ultimate strength of the system. Obviously, the increase in this ratio reduces the ultimate strength of the system. As shown in the figure, the ultimate strength is equal to $9450 \mathrm{kgf}$ for the obese rectangular sample, $8600 \mathrm{kgf}$ for the square sample and $7630 \mathrm{kgf}$ for the thin rectangular sample. 


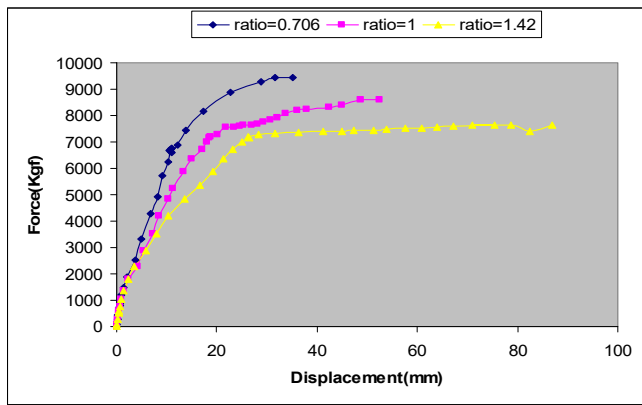

Fig. 6. Comparison of load-displacement curves for the analyzed samples

TABLE II. LISTS THE STIFFNESS OBTAINED FOR ALL SAMPLES

\begin{tabular}{|c|c|c|}
\hline Sample & Aspect ratio (h/b) & Stiffness (kgf / mm) \\
\hline 1 & 0.706 & 612.7 \\
\hline 2 & 1 & 467.8 \\
\hline 3 & 1.42 & 279.6 \\
\hline
\end{tabular}

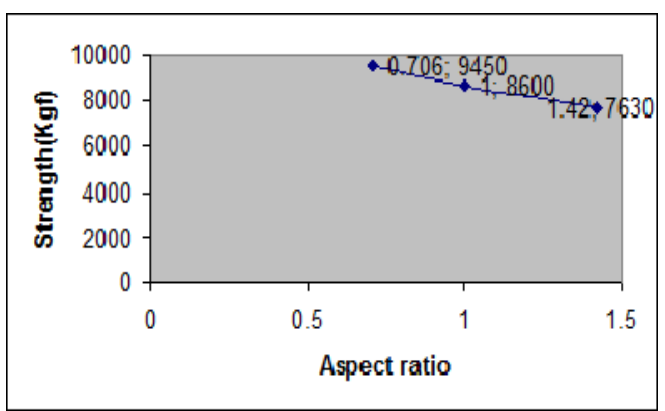

Fig. 7. Relationship between ultimate strength of the steel shear wall and aspect ratio of the panel

In this case, the ratio of the ultimate strength of obese rectangular sample to the square and thin rectangular samples is:

$$
\left\{\begin{array}{l}
\frac{9450}{8600}=1.09 \\
\frac{9450}{7630}=1.24
\end{array}\right.
$$

The ratio of the ultimate strength of the square sample to the thin rectangular sample is:

$$
\frac{8600}{7630}=1.13
$$

Obviously, ultimate strength of the obese rectangular sample is $\sim 9 \%$ higher than the ultimate strength of the square sample and $\sim 24 \%$ higher than that of thin rectangular sample. Moreover, the ultimate strength of the square sample is $\sim 13 \%$ higher than that of the thin rectangular sample.

\section{CONCLUSION}

Steel plates buckle when the limit load is reached. However, this does not imply systemic instability. As shown in experimental curves, there are jumps in some parts. In this load balance, the plate buckles and stiffness decreases in the loaddisplacement curve. In the buckling point, as the load increases, the system reaches a new equilibrium by geometric deformation. Simultaneously, the system shifts from in-plane shear to diagonal tension. After the buckling point, stiffness increases as the load increases and diagonal tension is formed. Diagonal post-buckling plate does not imply systemic instability. Comparison of load-displacement curves obtained from experiments and finite element ANSYS shows that analytic stiffness is higher than experimental stiffness; because experimental plates are not fully flat, while finite element analysis assumes that the plate is completely flat.

\section{REFERENCES}

[1] AISC, Seismic provisions for structural steel buildings. ANSI/AISC 341-10. American Institute of Steel Construction, Inc., Chicago, Illinois. 2010

[2] M. Bruneau, C. M. Uang, R. Sabelli, Ductile design of steel structures. 2nd ed. New York: McGraw-Hill, 2011

[3] Canadian Standards Association (CSA), Design of steel structures. CAN/CSA S16-09. Willowdale, Ontario, Canada. 2009

[4] R. G. Driver, G. L. Kulak, D. J. L. Kennedy, A. E. Elwi, Seismic behavior of steel plate shear walls, Structural engineering report 215, Department of Civil Engineering, University of Alberta, Edmonton, Alberta, Canada. 1997

[5] H. C. Guo, J. P. Hao, Y. H. Liu, "Behavior of stiffened and unstiffened steel plate shear walls considering joint properties", Thin-Walled Structures, Vol. 97, pp. 53-62, 2015

[6] F. Hatami, A. Ghamari, A. Rahai, "Investigating the properties of steel shear walls reinforced with Carbon Fiber Polymers (CFRP)", Journal of Constructional Steel Research, Vol. 70, pp. 36-42, 2012

[7] M. Rezai, Seismic behavior of steel plate shear walls by shake table testing. PhD thesis, University of British Columbia, Vancouver, BC, Canada. 1999

[8] T. Roberts, S. Sabouri Ghomi, "Hysteretic characteristics of unstiffened plate shear panels", Thin-Walled Structures, Vol. 12, No. 2, pp.145-62, 1991

[9] R. Sabelli, M. Bruneau, Steel plate shear walls (AISC design guide) Chicago, Illinois: American Institute of Steel Construction, Inc. 2007

[10] S. Sabouri Ghomi, T. M. Roberts, "Nonlinear dynamic analysis of steel plate shear wallsincluding shear and bending deformations", Engineering Structures, Vol. 14, No. 5, pp. 309-317, 1992

[11] S. Sabouri Ghomi, The systems resistant against lateral loads; an introduction on steel shear walls, Angizeh, Tehran, 2001

[12] C. Topkaya, C. O. Kurban, "Natural periods of steel plate shear wall systems", Journal of Constructional Steel Research, Vol. 65, No. 3, pp. 542-551, 2009

[13] H. Veladi, A. Armaghani, A. Davaran, Experimental analysis of periodic behavior of steel shear walls, University of Tabriz, Iran, 2006 